\title{
ЦЕННОСТНЫЙ ПОДХОД В ПРОЦЕССЕ ОБРАЗОВАТЕЛЬНОЙ ДЕЯТЕЛЬНОСТИ (ПРЕПОДАВАНИЕ БИОЛОГИИ)
}

\section{VALUE APPROACH IN THE PROCESS OF EDUCATIONAL ACTIVITY (TEACHING BIOLOGY)}

A. Naidan

Summary: With regard to the teaching of biology, the fifth grade is a special case, since the continuity with the previous academic year is less pronounced than all other subjects. The directions of increasing interest in the content and cognitive side of the subject, considered in the literature, pay little attention. This determined the direction of our pedagogical experiment, which consisted in each student completing mini-projects about plants in the Red Book of Russia. The results of the experiment indicate an increase in interest in the subject (the cognitive component), as well as the formation of an aesthetic and value approach to nature.

Keywords: value approach, nature protection, biology lessons, fifth grade, educational projects.

\author{
Найдан Алексей Николаевич \\ аспирант, Московский Педагогический \\ Государственный Университет \\ NaydanAlexey@gmail.com
}

Аннотация: В отношении преподавания биологии, пятый класс представляет собой особый случай, поскольку преемственность с предыдущим учебным годом выражена менее всех других предметов. Рассмотренные в литературе направления повышения интереса к содержательной и когнитивной стороне предмета, мало внимания уделяют ценностной составляющей. Этим определялась направленность проведенного педагогического эксперимента, заключающегося в выполнении каждым учеником мини-проектов о растениях Красной книги России. Результаты эксперимента свидетельствуют о повышении интереса к предмету (когнитивная составляющая), а также о формировании эстетического и ценностного подхода в отношении к природе.

Ключевые слова: ценностный подход, охрана природы, уроки биологии, пятый класс, учебные проекты.
$\Pi$ ринятие системы федеральных образовательных стандартов (ФГОС) ознаменовало и смену парадигм образования. Прежняя, знаниевая, имела целью вооружить учащихся максимальным количеством знаний, умений и навыков. Новая, компетентностная, ставит целью формирование современного человека как социально активной и деятельной личности, профессионала и гражданина, владеющего не набором фактов, а способами и технологиями их получения [8].

В свете этой концепции, содержание образования вообще и каждого преподаваемого предмета в частности предусматривает не только формирование опыта познавательной и практической деятельности, но и формирование опыта эмоционально-ценностных отношений [1]. Этот тезис, высказанный еще в отношении ФГОС первого поколения, не теряет своей актуальности и сегодня, определяя важности ценностного подхода к содержанию урока по любому предмету - в том числе и по биологии.

Еще одной непременной составляющей современной парадигмы образования видится ее преемственность - как в содержании образования, так и в морально-нравственном, ценностном контексте - от класса к классу, от одной учебной ступени к другой. Однако и в наши дни проблема такой преемственности остается актуальной, и прежде всего в отношении «перехода» между младшим и средним звеном [9]. В статье данного автора проблема рассмотрена в целом, хотя и во многих аспектах (в том числе ценностно-этическом). Однако те же вопросы в отношении преподавания дисциплин биологического цикла в доступной литературе систематически не рассмотрены - но именно в этом видится актуальность нашего исследования.

Более того, в отношении дисциплин биологического цикла эти вопросы имеют значительное своеобразие, которое, на наш взгляд, заключается в следующем.

Во-первых, знания о природе в младших классах даются в курсе «Окружающий мир» обобщенно, в сочетании с другими темами и проблемами. В результате познавательная составляющая формируется у учащихся активно, но становление адекватного ценностного отношения к природе при этом замедлено. Основное противоречие известно: между необходимостью всестороннего учета воспитательных моментов и недостатком учебного времени, которое обычно направляется на решение основных задач урока.

Во-вторых, значимо также, что преподавание биологии, как систематизированного предмета, начинается с пятого класса, притом, в соответствии с иерархией уровней живой природы - с ботаники. С точки зрения последовательности учебных задач это оправдано, но восприятие детьми этого предмета неоднозначно. «Даже само слово «ботаник» в наши дни стало нарицательным, 
имеющим негативно-иронический оттенок» - резюмирует в своей статье Т.В. Максимова, подчеркивая необходимость придать ботаническим знаниям их подлинный статус в ходе изучения курса биологических дисциплин школе [4].

B-третьих, многогранный опыт активизации интереса к предмету очень прогрессивен и интересен, различны и способы достижения педагогического эффекта: с помощью лабораторных работ [2], учебно-исследовательских факультативов [5], системы научно-исследовательских мини-проектов [10]. Однако во всех этих направлениях основной акцент интереса, привлечения внимания, активной самостоятельной деятельности приходится именно на познавательную составляющую, и именно таковая оценивается в качестве результата. Вопрос же исследования формирования ценностного отношения к природе в результате подобных занятий (притом именно в пятом классе) в текущей научно-педагогической периодике практически не отражен.

Вместе с тем, пути такого исследования и его методики рекомендуют (хотя и не приводят практических результатов) в своей статье практические педагоги средней школы С.А. Николаева и О.В. Полявина [7].

Для решения заявленных нами для исследования задач, оптимален опросник «ЭЗОП» («эмоции - знания охрана - польза»). Целью этого метода, разработанного В.А. Ясвиным и С.Д. Дерябо, является определение типа доминирующей установки учащихся в отношении природы:
- эстетического (Э) - восприятие природы как объекта красоты

- когнитивного (К) - интерес к знаниям о природе, ее изучению,

- ценностно-этического (Ц) - отношение к природе как объекту сбережения, охраны;

- прагматического (П) - акцентирование «полезности» природы для человека [3].

Методика предназначена для учащихся среднего звена, поэтому может быть применена и для пятиклассников. Она содержит 12 пунктов, каждый из которых состоит из стимульного слова и - слов-ассоциаций (среди которых опрашиваемый должен выбрать одно, характеризующее тип отношения к данному объекту природы). Количество выборов того или иного типа представляется в процентном отношении от максимального возможного, а затем им присваиваются соответствующие ранги: $1,2,3,4$..

Проведенное в начале учебного года в пятом классе тестирование по этой методике дало следующие результаты (рис. 1): преобладало прагматическое отношение к природе, на втором месте оказалось познавательное, на третьем - эстетическое, и на последнем месте - этическое. Такое положение можно объяснить тем, что в изучавшем в прошлом учебном году курсе «Окружающий мир», помимо знаниевой составляющей, большое место занимали вопросы использования природных богатств - соответственно этому сформировались и мнения учащихся. То есть, сформированность осознанного ценностного отношения учащихся к природе недостаточна, и для коррекции этой ситуации необходим педа-

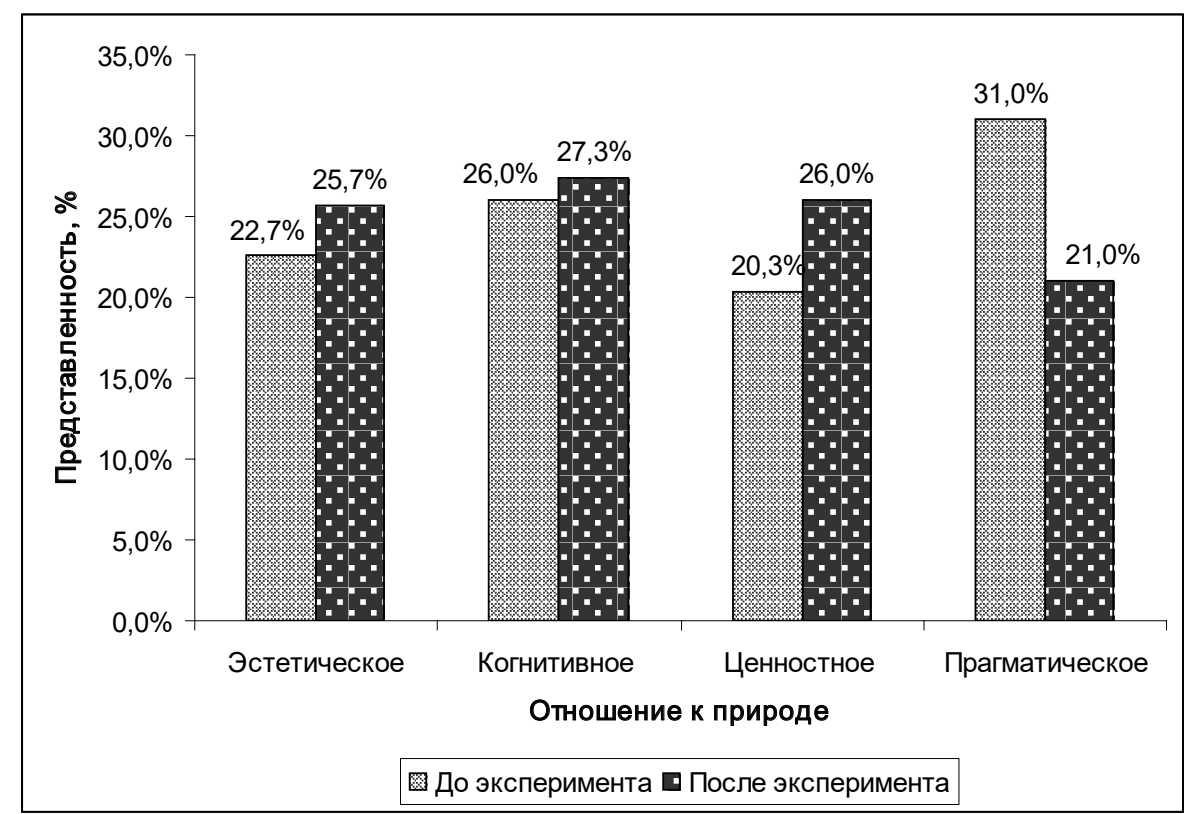

Рис. 1. Сравнительная характеристика отношения к природе в исследуемом классе в результате педагогического эксперимента 
гогический эксперимент.

Сущность его состояла в том, что каждый из учащихся исследуемого пятого класса в течение учебного года выполнял один самостоятельный учебный мини-проект рассказ об одном из растений Красной книги России. Выполнение предусматривало не только информацию о месте произрастания и биологических особенностях, но и об его эстетических характеристиках, а также о причинах, почему оно оказалось на грани исчезновения.

Формат мини-проекта предусматривал пятиминутный доклад с применением необходимого, самостоятельно подобранного учеником иллюстративного материала. Он заслушивался обычно в конце урока, перед завершающей частью. Достоинствами проекта необходимо признать следующие:

- ученики не самостоятельно подбирали информацию и иллюстративный материал, ввиду чего формировались навыки поиска и использования информации:

- выделяя самое главное, ввиду краткости доклада, они приобретали опыт целенаправленных действий с информацией;

- представляя доклад перед классом, они приобретали навык выступления перед аудиторией, который в младших классах формируется обычно недостаточно.

Главным же результатом педагогического эксперимента следует считать изменение ценностного подхода у учащихся в результате него (рис. 1). Все три позитивных параметра сблизились и практически выровнялись (при небольшом преимуществе когнитивного), параметр же прагматического отношения к природе снизился до приемлемого уровня.

Данные педагогического наблюдения на уроках позволяют констатировать также повысившийся общий интерес к урокам: повысилась активность ответов, ученики стали чаще и обоснованнее задавать вопросы, что подтверждает выявленный некоторый приоритет когни- тивной составляющей.

Следует признать также тезис, изложенный во ФГОС среднего образования и рассмотренный во многих работах - о необходимой интегративности обучения и значении межпредметных связей в соответствии с ФГОС [6]. В отношении данной темы это прежде всего касается литературы и краеведения, поскольку им принадлежит дополнительная роль в формировании ценностно-эстетических представлений о природе.

В целом же из проведенной работы необходимо сделать следующий ряд выводов:

1. В отношении преподавания биологии пятый класс представляет собой особый случай, поскольку преемственность с предыдущим учебным годом выражена менее всех других предметов - как в содержательном, так и в мировоззренческом аспекте;

2. В доступной литературе исследованы различные направления и методики повышения интереса к содержательной и когнитивной стороне предмета, но мало внимания уделено ценностному подходу к нему. Это определяло направленность проведенного нами педагогического эксперимента, заключающегося в выполнении каждым учеником мини-проектов о растениях Красной книги России.

3. Предложенный педагогический эксперимент способствовал не только повышению интереса к предмету (когнитивная составляющая), но и формированию эстетического и ценностного подхода в вопросах природы.

Вместе с тем, нуждаются в дополнительном исследовании и другие вопросы ценностного подхода - тем более, что соответствующие тестовые методики существуют и для них. Прежде всего, это определение ведущего типа мотивации взаимодействия с природными объектами, а также диагностическая методика «НАТУРАФИЛ», результаты которой характеризуют особенности субъективного отношения к природе. Такая диагностика должна составить основу последующих наших исследований.

ЛИТЕРАТУРА

1. Беляева Е.Н. Эмоционально-ценностное отношение учащихся к живой природе как одно из условий развития личности школьника // Наука и школа. 2012. - № 1. - С. 81-84.

2. Гринькова 0.В. Организация обучения школьников 5 классов предмету "Биология" в условиях реализации ФГоС // Проблемы педагогики - 2016 - № 2. - С $32-39$.

3. Дерябо С.Д. Ясвин. В.П. Экологическая педагогика и психология. - Ростов-на-Дону.: Феникс. - 1996. - 480 с.

4. Максимова Т.В. Новые приемы в преподавании практической части ботаники на уроках и во внеурочной деятельности // Science for Education Today. 2013. - № 3. - C. 5-9.

5. Матвеева А.В. Формирование экологической компетентности учащихся средствами проектной технологии // Вестник Мининского университета - 2015 № 2. - C. 28-37. 
6. Машкова Н.Н. Шувалова И.В. Реализация интегративного подхода в процессе обучения ботанике в школе // Интеграция образования. - 2013 - № 4. C. 110-117.

7. Николаева С.А., Полявина О.В. Теоретические аспекты формирования ценностного отношения к природе у учащихся основной школы // Наука и перспективы. - 2018. - № 3. - С. 70-73

8. Рагозина Г.А., Коняхина И.В. Значение компетентностной парадигмы в образовании // Приволжский научный вестник/ - 2014/ - № 2. - С. 159-166.

9. Шацкая М.В. Психолого-педагогические основы преемственности на начальном и среднем этапах обучения школьников // Евразийский Союз Ученых. 2020. -№ 1. - С. 68-71.

10. Хамидуллина Р.Р. Метод проектов в обучении биологии // Science Time. - 2017. - № 12. - 581-586.

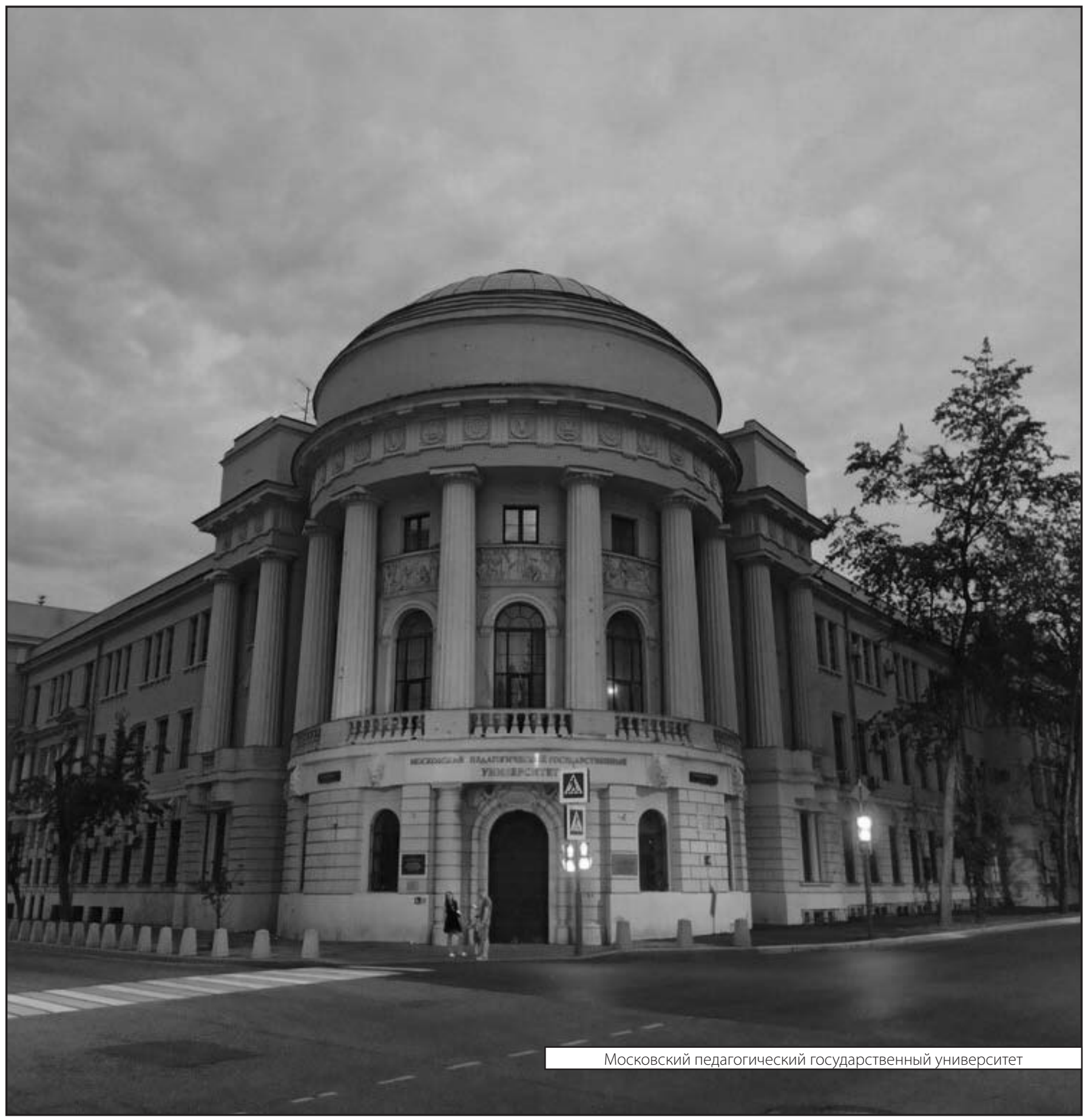

